\title{
Modeling of the Unburned Carbon in Fly Ash
}

\author{
Weiping YAN, Jun LI \\ Key Laboratory of Condition Monitoring and Control for Power Plant Equipment of Ministry of Education, \\ North China Electric Power University, Baoding, China \\ Email:lj2110271@163.com
}

\begin{abstract}
Numerical simulation of the content of unburned carbon in fly ash on the 300MW tangentially pulverized coal fired boiler is performed by the numerical simulation software COALFIRE, which is based on international advanced TASCFLOW software platform. Firstly, take the result of calculation of number value as the sample, and then set up the support vector machine model of unburned carbon content on the boiler. The relative error between the predicted output and measured value is $0.00186 \%$, which proves the modeling is good for the unburned carbon in fly ash predict.
\end{abstract}

Keywords: numerical simulation, unburned carbon content, support vector machine

\section{Introduction}

The unburned carbon in fly ash is the important data which reflects the combustion efficiency of the coal fired boiler in thermal power plant, but the content of unburned carbon in fly ash of the coal fired boiler is influenced by so many kinds of factors which are difficult to be measured in real time [1-3].

At present, there are lots of the researches about the monitor of the content of unburned carbon in fly ash in real time in domestic and international. Most of them are concentrated on the technology of the measurement equipment and software [4-6]. The equipment of the content of unburned carbon in fly ash has many problems, such as the block of sample tube, complicated extra equipment, many influence factors about the precision of the measurement, high cost of the fabrication and the high request of maintain, etc. Moreover, the traditional soft measurement technology is almost all used the artificial neural network method to build the model, because the study algorithm of the neural network adopts the experience risk and minimizes the principle, lacks of quantitative analysis and theory result with complete mechanism. At the same time, for the reason of it is limited in quantity to survey samples, it will cause the question of overstudying and the ability of generalization badly, etc. Therefore, there is very great limitation exist in the measurement of the content of unburned carbon in fly ash based on the artificial neural.

As a kind of new statistics learning method, support the vector machine (Support Vector Machine, SVM) uses the principle of the structure risk minimize (SRM), which solved the problem of generalization in the theory of machine studying effectively. The goal function of the structure risk minimize (SRM) has suppressed the phe- nomenon of owed and passed studying effectively, and it can get the good ability of generalization. The algorithm is turned into a secondary programming and gets optimum point of global. It has solved local minimum problem in the neural network. Its topological structure only relates to support the vector and has reduced the calculating amount. The computational speed is fast, which is suitable for online application. The method is suited to study in little sample. Support vector machine has already become the important research means between the pattern-recognition and the data excavate field at present $[7,8]$.

In the limited sample studying system [9], because it has the wild value in the sample, the statistics study theory of V. N. Vapnik thinks it has caused the reducing of minimum guaranteed risk value. It also caused low category precision in the category questions. Regression will have the phenomenon of "over fitted" or "over trained", and the ability of generalization of the study drops greatly too. On the condition of training samples is limited, the selection of training collection influences the ability of generalization of study machine obviously. That is to say, the ability of generalization not only relates to the study algorithm, but also relates to the selection of training collection. When choosing the model sample, the existing method always uses the unburned carbon in fly ash of the boiler hot condition as training the sample [4-6]. Because the combustion operating mode in the pulverized coal fired boiler is very complicated, involving the course in many aspects of burning, flowing, conducting heat etc, receives such as the influence in proportion, nature of the coal, density and fineness of coal flow, wind velocity, load of boiler, etc. Additionally, these factors often influence each other and interweave each other, which have 
increased the complexity of the combustion process even more, thus it causes changeable of the unburned carbon in fly ash. Adding the restriction of the on site condition, it is more difficult to get the intact sample of unburned carbon in fly ash from the operating mode of the boiler.

Using the method of numerical simulation to calculate the content of unburned carbon in fly ash of the boiler has satisfied accuracy, whose variation tendency predicted can meet the need of combustion adjustment for operation actually. However, its amount of calculation will consume much time. It will consume a large amount of time even used for optimize design off line. It makes it difficult to use in monitoring and optimizing online directly.

To the question of appealing, this paper adopts the coal-fired pulverized boiler furnace numerical simulation software COALFIRE, to calculate the content of unburned carbon in fly ash off-line under many kinds of burning operating modes of the boiler. Regard the result of calculation of number value in advance as the training sample of the model of vector supporting machine. It makes the model not only has the precision of the numerical simulation, but also can applies the result in the online system of content of unburned carbon in fly ash monitoring and optimizing.

\section{Pre-Numerical Calculation}

\subsection{Object of Simulation}

Object of the simulation is the boiler of DG1025/18.2-IV, which was made by the Don Fang boiler factory in China.

\subsection{The Method of Numerical Simulation}

It chooses the calculate area between the bottom of the furnace hopper and the angle of flame diverter on the top of the furnace. It takes the width of the furnace as the $\mathrm{X}$ direction, the depth of the furnace as the Y direction, the height of furnace as the $\mathrm{Z}$ direction. Divide 160 unit areas, 508896 mesh altogether. The numerical simulation adopts the three-dimensional stable state to calculate. Adopt standard $\mathrm{k}-\varepsilon$ equation model to simulate the turbulent gaseous phase of flow; use the particle track model at random to solve the solid particle phase problem; adopt P1 radiate models to solve the radiation Conduct heat; adopt the single step response model to the release of the coal pulverized volatile matter; have adopted the motive force model of spreading to the burning of the coke; adopt the PDF model of conservation scalar to simulate the non-premixed combustion and the non-cross mesh SIMPLE method to solve the flowing field of the gaseous phase. Having identified the convergence by the residual, all of the relative error of the calculating amounts (for instance, the relative error that $\mathrm{u}, \mathrm{v}, \mathrm{w}, \varepsilon$, etc.) must be smaller than the value of $1.0 \times 10^{-4}$. Take it as the convergence criterion.

\subsection{The Operating Mode of Calculation}

Consider the change of unburned carbon in fly ash with the change of the nature of coal, coal fineness, boiler load, distribution of secondary air, withdrawal or input of tertiary air, etc.

\subsection{Comparison and Analysis of Results of the Unburned Carbon in Fly Ash}

The unburned carbon content in fly ash of outlet of furnace can be received through the numerical simulation. The actual measurement value of unburned carbon also can get by the online monitoring system of carbon content of unburned carbon in fly ash which located in front of the air pre-heater at the same time. The result of calculating simulation and hot surveying value of unburned carbon content in fly ash are as Figure 1 shows. Figure 1 shows that the actual measurement value is higher than the result of numerical simulation, the greatest relative error is $0.07 \%$ after revising and the minimum relative error is $0.02 \%$. Considering the error of the surveying value, the result of calculation of number value and hot operating mode surveying value are identical better.

\section{The Model of Unburned Carbon in Fly Ash Based on Support Vector Machine}

\subsection{The Introduce of Support Vector Regression}

The basic problem of regression is to find a function $f \in F$ (F-Union of function) and make the expected risk function as follow minimum [10-15].

\subsection{Unburned Carbon Content in Fly Ash Model Based on Support Vector Machine}

- The choice of input and output parameter of the model

According to the condition of the pre-numerical simulation in advance, adopt the flowing as parameter of inputting, include the boiler load, rate of powder quality,

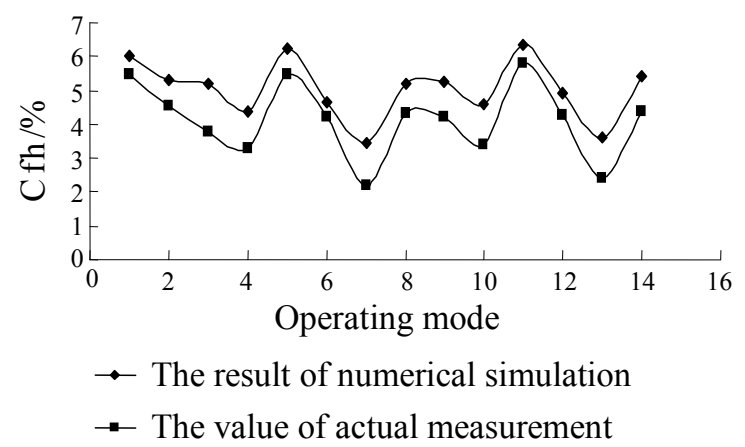

Figure 1. The unburned carbon content under various operating conditions 
fineness of pulverized coal, wind velocity of secondary air and tertiary air, tilt angle of burner, net calorific power, volatile, ash content and moisture content of coal. The amount of adjustable parameter is 22. Regard carbon content of flying ash as the parameter of outputting, and use the supporting vector machine to set up the carbon content characteristic model of flying ash.

- Selecting of kernel function

Selecting of kernel function influences the regression analysis of support vector machine obviously, but does not have a ripe theory about it at present yet [16]. The paper selected the radial kernel function [17].

- Constitution of sample union and the selecting of algorithm parameter

The sample union is structured by the result of precalculation in different operating condition of boiler. Taking the result of $1 \sim 2 、 4 \sim 8 、 10 \sim 14$ operating condition as the training sample, the result of $3 、 9$ operates condition as test sample. Adopting the radial kernel function to regression analysis, the precision of model $\varepsilon$ is 0.0001 .

- The result and the analysis

The trained result shows as follows: the relative error of the output of predicting is $0.00186 \%$. The predicting output and the relative error of the test sample of operating condition 3 and 9 show as Table 1. It is indicating that the output error of support vector machine model is very small, and its identical degree of data is quite good. It is proved that this model has gotten the correct corresponding behavior between the input and output. This proves that the modeling of the unburned carbon in fly ash based on numerical simulation and support vector machine algorithm on the $300 \mathrm{MW}$ tangentially pulverized coal fired boiler is successful.

\section{Conclusions}

The unburned carbon content in fly ash of tangentially pulverized coal is influenced by so many factors. The factors also influence each other. Therefore, it is difficult to predict and control the unburned carbon content in fly ash. By the pre-calculating, the precision result of unburned carbon content in fly ash can be gotten. After it is fixed by the practice measurement in different boiler operating condition, it can be taken as the training test

Table 1. The comparison between the predict value of support vector machine model and pre-calculation value of unburned carbon content in fly ash

\begin{tabular}{cccc}
\hline $\begin{array}{c}\text { Operating } \\
\text { condition }\end{array}$ & $\begin{array}{c}\text { Numerical } \\
\text { simulation } \\
(\%)\end{array}$ & $\begin{array}{c}\text { The result of } \\
\text { model of } \\
\text { support vector } \\
\text { machine }(\%)\end{array}$ & $\begin{array}{c}\text { The absolute } \\
\text { value of relative } \\
\text { error }(\%)\end{array}$ \\
\hline 3 & 5.18 & 5.152 & 0.541 \\
9 & 5.23 & 5.214 & 0.306 \\
\hline
\end{tabular}

sample of the support vector machine model. The simulating result shows that the predict result and the result of practice measurement of unburned carbon content in fly ash of boiler concordances are better. It provides the effective method for applying the numerical simulation result for the online monitor of boiler burn state parameter, whose character is to get accurate result but consume enormous time during computational process. If combining the overall situation seeking excellent algorithm, it can make the boiler reach optimum operating mode, and improve security and economy of the boiler.

\section{REFERENCES}

[1] M. H. Fan and R. C. Brown, "Precision and accuracy of photo acoustic measurements of unburned carbon in fly ash [J]," Fuel, Vol. 80, No. 11, pp. 1545-1554, 2001.

[2] K. Styszko-Grochowiak, J. Golas, H. Jankowski, et al., "Characterization of the coal fly ash for the purpose of improvement of industrial on-line measurement of unburned carbon content [J]," Fuel, Vol. 83, No. 13, pp. 1847-1853, 2004.

[3] A. K. Ouazzane, J. L. Castagner, A. R. Jones, et a1., "Design of an optical instrument to measure the carbon content of fly ash [J]," Fuel, Vol. 81, No. 15, pp. 1907-1911, 2002.

[4] H. Zhou, H. B. Zhu, T. H. Zeng, et a1., “Artificial neural network modelling on the unburned carbon in fly ash from utility boilers [J]," Proceedings of the CSEE, Vol. 22, No. 6, pp. 96-100, 2002. (in Chinese)

[5] X. T. Fang and N. Y. Ye, "A system forpredicting the anburned carbon of the fly ash from utility boilers based on BP artificial neural netwoks [J]," Jouunal of Huazhong Uruversity of Science \& Technology, Nature Science Edition, Vol. 31, No. 12, pp. 75-77, 2003. (in Chinese)

[6] M. Sebastia,I. F. dez Olmo, and Angel Irabien, "Neural network prediction of unconfined compressive strength of coal fly ash cement mixtures [J]," Cement and Concrete Research, Vol. 33, No. 8, pp. 137-145, 2003.

[7] G. Y. Zhang and J. Zhang, "Fuzzy SVM-based multilevel binary tree classifier for fault diagnosis of hydroturbine speed regulating system $[\mathrm{J}]$," Proceedings of the CSEE, Vol. 25, No. 8, pp. 100-104, 2005. (in Chinese)

[8] Y. C. Li, T. J. Fang, and E. K. Yu, "Study of support vector machines for short-term load predicting [J]," Proceedings of the CSEE, Vol. 23, No. 6, pp. 55-59, 2003. (in Chinese)

[9] Y. Wang, Z. H. Zhou, and A. Y. Zhou, "The apply of machine study [M]," The Publish House of Tsinghua University, Beijing, pp. 1-27, 2006.

[10] A. Smola and B. Scholkopf, "A tutorialon support vector regression [R]," Royal Holoway College, London,1998.

[11] V. N. Vapnik, "The nature of statistical learning theory [M]," Springer, New York, 1999.

[12] G. Z. Li, M. Wang, H. J. Zeng (translate), N. Cristianini, 
J. Shawe-Taylor (write), "Introduction of support vector [M]," The Publish House of Electric Industry, Beijing, 2004.

[13] X. G. Zhang (translate), Vapnik (write), "Theory of statistic study [M]," The Publish House of Electric Industry, Beijing, 2004.

[14] X. G. Zhang, "Introduction to statistical learning theory and support vector machines [J]," ACTA Automatica Sinica, Vol. 26, No. 1, pp. 32-43, 2000.

[15] X. D. Wang and J. Q. Wang, "A survey on support vector machine traing and testing algorithms $[\mathrm{J}]$," Computer
Engineering and Applications, Vol. 40, No. 13, pp. 75-78, 2000

[16] S. S. Keerthi and C. J. Lin, "A symptotic behaviors of support v machines with Gaussian kernel [J]," Neural Computation, pp. 1667-1689, 2003.

[17] C. L. Wang and H. Zhou, et al., "Support vector machine modeling on the unburned carbon in fly ash [J]," Proceedings of the CSEE, Vol. 20, No. 25, pp. 72-76, 2005. (in Chinese) 